\title{
Bismuth-Catalyzed Oxidative Coupling of Arylboronic Acids with Triflate and Nonaflate Salts
}

\author{
Oriol Planas, Vytautas Peciukenas, and Josep Cornella*
}

Cite This: J. Am. Chem. Soc. 2020, 142, 11382-11387

Read Online

ABSTRACT: Herein we present a Bi-catalyzed cross-coupling of arylboronic acids with perfluoroalkyl sulfonate salts based on a $\mathrm{Bi}(\mathrm{III}) / \mathrm{Bi}(\mathrm{V})$ redox cycle. An electron-deficient sulfone ligand proved to be key for the successful implementation of this protocol, which allows the unusual construction of $\mathrm{C}\left(\mathrm{sp}^{2}\right)-\mathrm{O}$ bonds using commercially available NaOTf and KONf as coupling partners. Preliminary mechanistic studies as well as theoretical investigations reveal the intermediacy of a highly electrophilic Bi(V) species, which rapidly eliminates phenyl triflate.

F unctional groups such as the trifluoromethanesulfonate 1 (triflate, OTf) or the nonafluorobutanesulfonate (nonaflate, ONf) are highly useful moieties when present in organic compounds, especially when attached to a carbon atom $(\mathrm{C}-$ OTf or C-ONf). ${ }^{1}$ Indeed, $\mathrm{C}\left(\mathrm{sp}^{2}\right)-\mathrm{OTf}$ and $\mathrm{C}\left(\mathrm{sp}^{2}\right)-\mathrm{ONf}$ have been utilized as surrogates of aryl halides ( $a k a$ pseudohalides) due to their ability to heavily polarize the $\mathrm{C}-\mathrm{O}$ bond, facilitating oxidative addition by d-block metals. This strategy has been largely exploited with a myriad of combinations of both transition metals and coupling partners, ${ }^{2}$ thus placing aryl triflates and nonaflates as routine electrophiles in this large arena. ${ }^{3}$ From the organometallic standpoint, OTf anions have also many attractive features. The coordinating properties of triflate anions have been a matter of intense debate in the recent literature. ${ }^{4}$ However, it is evident that differently than $\mathrm{Ar}-\mathrm{Cl}$, oxidative addition complexes of $\mathrm{Ar}-$ OTf would result in a remarkably weaker interaction of the OTf anion and the metal center in solution. Furthermore, in polar and coordinating solvents the OTf anion is generally relegated to the outer sphere, leaving a vacant coordination site (Figure 1A), which has been exploited for a variety of organometallic and coordination purposes. ${ }^{5}$ Yet, the great attributes of OTf anions-highly electronegative, poor nucleophiles and labile ligands-inherently situates them as one of the foulest anions to undergo $\mathrm{C}-\mathrm{O}$ reductive elimination. ${ }^{6}$

Many examples with high-valent transition metals have been reported to accommodate OTf anions in the primary coordination sphere. ${ }^{7}$ However, reductive elimination primarily occurred at other anionic ligand sites and the M-OTf bond remained unaltered. ${ }^{8}$ During the synthesis of trisubstituted olefins, Gaunt and co-workers suggested that $\mathrm{C}\left(\mathrm{sp}^{2}\right)-\mathrm{OTf}$ bonds could be formed through an unusual reductive elimination from a $\mathrm{Cu}$ (III) center, ${ }^{9}$ although further evidence was not provided. Indeed, examples of well-defined transition metal complexes that forge $\mathrm{C}\left(\mathrm{sp}^{2}\right)$-OTf bonds still remain elusive. Notwithstanding, the development of a catalytic protocol which enables the formation of $\mathrm{Ar}-\mathrm{OTf}$ from the corresponding organometallic reagent $(\mathrm{Ar}-\mathrm{M})$ and a com-

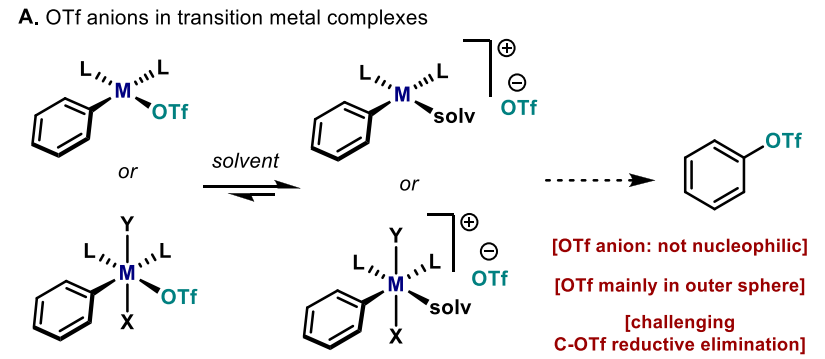

B. This work: Bi-catalyzed coupling of triflate and nonaflate with arylboronic acids

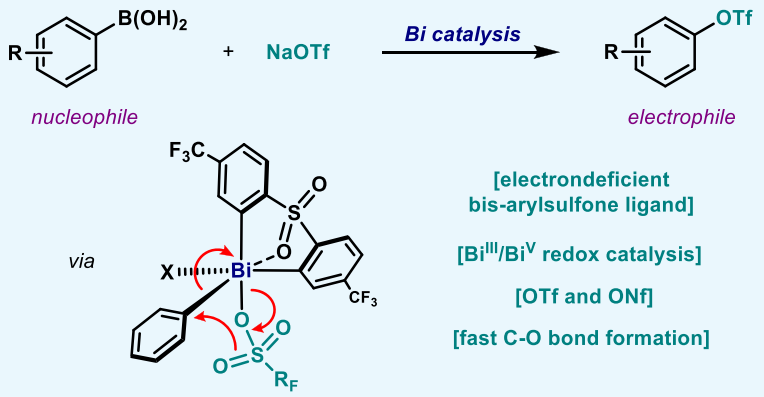

Figure 1. (A) OTf anions as ligands in transition metal chemistry. (B) Catalytic Ar-OTf formation through a $\mathrm{Bi}(\mathrm{III}) / \mathrm{Bi}(\mathrm{V})$ redox system.

mercially available triflate salt (MOTf) would be highly desirable from both the synthetic and fundamental point of view.

Our group has recently started a program to study the catalytic redox properties of bismuth $(\mathrm{Bi})$ complexes, ${ }^{10}$ to facilitate transformations beyond the reactivity of transition

Received: May 15, 2020

Published: June 14, 2020 
metals. ${ }^{11}$ Hence, based on the known oxophilicity of $\mathrm{Bi}$ complexes $^{12}$ and their ability to bind triflate, ${ }^{13}$ we envisaged that an oxidative protocol based on the redox couple $\mathrm{Bi}(\mathrm{III}) /$ $\mathrm{Bi}(\mathrm{V})$ could fulfill this synthetic challenge. Indeed, a decade ago Mukaiyama and co-workers demonstrated that C-OTf bonds could be forged from $\mathrm{Bi}(\mathrm{V})$ compounds and HOTf, albeit in low yields. ${ }^{14}$ Inspired by this early precedent, herein we report on a catalytic oxidative coupling between arylboronic acids and triflate salts to furnish Ar-OTf species (Figure 1B). A rationally designed $\mathrm{Bi}$ complex bearing an electron-deficient diarylsulfone ligand unlocks a catalytic redox process and enables the use of triflate (OTf) and nonaflate (ONf) salts as coupling partners. Preliminary mechanistic investigations and theoretical analysis revealed that the $\mathrm{C}\left(\mathrm{sp}^{2}\right)-\mathrm{O}$ bond formation is extremely fast from $\mathrm{Bi}(\mathrm{V})$ and is suggested to proceed through a five-membered transition state.

We started our investigations by optimizing the coupling of phenylboronic acid (1a) with $\mathrm{NaOTf}$ to generate phenyltriflate (2a) (Table 1). Based on our previous studies on Bi-catalyzed

\section{Table 1. Optimization of the Reaction Conditions ${ }^{a}$}

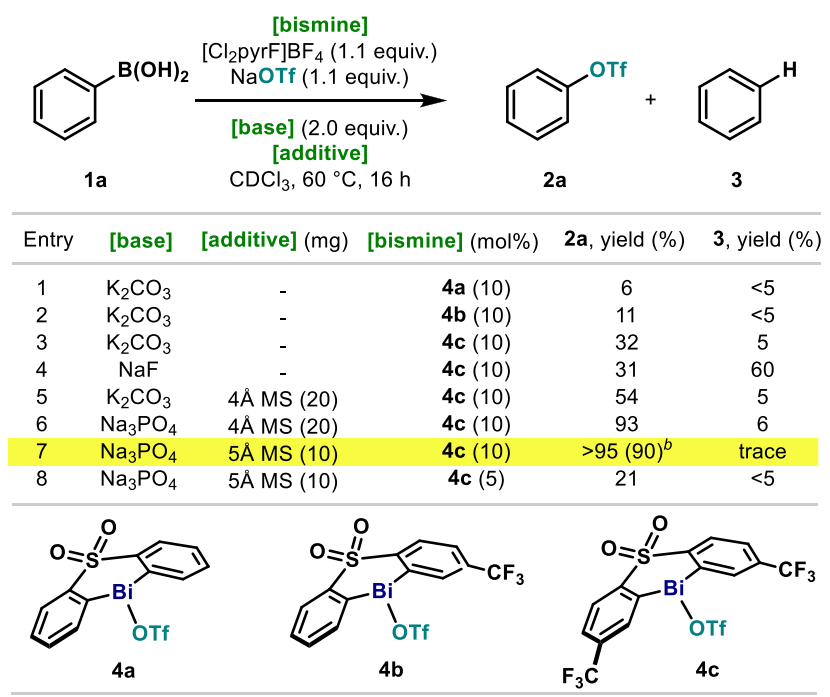

${ }^{a}$ Reactions performed at $0.025 \mathrm{mmol}$ of $\mathbf{1 a}$. Yields determined by ${ }^{19} \mathrm{~F}$ NMR using 1-fluoro-4-nitrobenzene as internal standard. ${ }^{b}$ Isolated yield of pure material of a reaction performed at $0.3 \mathrm{mmol}$ of $1 \mathrm{a}$.

fluorination, bismines featuring a diarylsulfone backbone (4ac) were selected as catalysts, ${ }^{15}$ together with $\mathrm{N}$-fluoro-2,6dichloropyiridinium tetrafluoroborate $\left(\left[\mathrm{Cl}_{2} \mathrm{pyrF}\right] \mathrm{BF}_{4}\right)$ as oxidant. To promote transmetalation, we selected $\mathrm{K}_{2} \mathrm{CO}_{3}$, as it has been recently demonstrated to be an excellent base for this purpose. ${ }^{16}$ In our initial attempts, the unsubstituted bismine catalyst (4a) provided no reactivity toward 2a (entry 1). However, when a $\mathrm{CF}_{3}$ group was introduced in meta-position to the $\mathrm{Bi}(\mathbf{4 b})$, an encouraging $11 \%$ of $2 \mathrm{a}$ was obtained; interestingly, the formation of protodeboronation byproduct 3 was largely suppressed (entry 2). In line with these results, when two $\mathrm{CF}_{3}$ are introduced in the backbone of the sulfone (4c) the reactivity toward $2 \mathrm{a}$ increased to $32 \%$, while the formation of 3 was still largely reduced (entry 3 ). When $\mathrm{K}_{2} \mathrm{CO}_{3}$ is replaced by $\mathrm{NaF}$, a reversed trend in the product distribution is observed, substantially favoring undesired 3 (entry 4). Surprisingly, addition of $4 \AA$ molecular sieves (MS) boosted the formation of $2 \mathrm{a}$ to $54 \%$ yield, while formation of 3 was still minimized (entry 5). Remarkably, when $\mathrm{K}_{2} \mathrm{CO}_{3}$ was replaced by the weaker $\mathrm{Na}_{3} \mathrm{PO}_{4}$, nearly quantitative formation of $2 \mathrm{a}$ was achieved (entry 6 ). The use of $5 \AA$ MS proved crucial to completely suppress the formation of 3 , thus obtaining the desired $\mathbf{2 a}$ in $>95 \%$ yield (90\% isolated) (entry 7 ). Unfortunately, lower catalyst loadings resulted in poor yields (entry 8).

With the optimal conditions in hand, the scope of the Bicatalyzed $\mathrm{C}\left(\mathrm{sp}^{2}\right)-\mathrm{OTf}$ bond reaction was investigated using a variety of arylboronic acid derivatives (Table 2). The

Table 2. Scope of the Bi-Catalyzed Oxidative Coupling of Arylboronic Acids and Sodium Triflate ${ }^{a}$

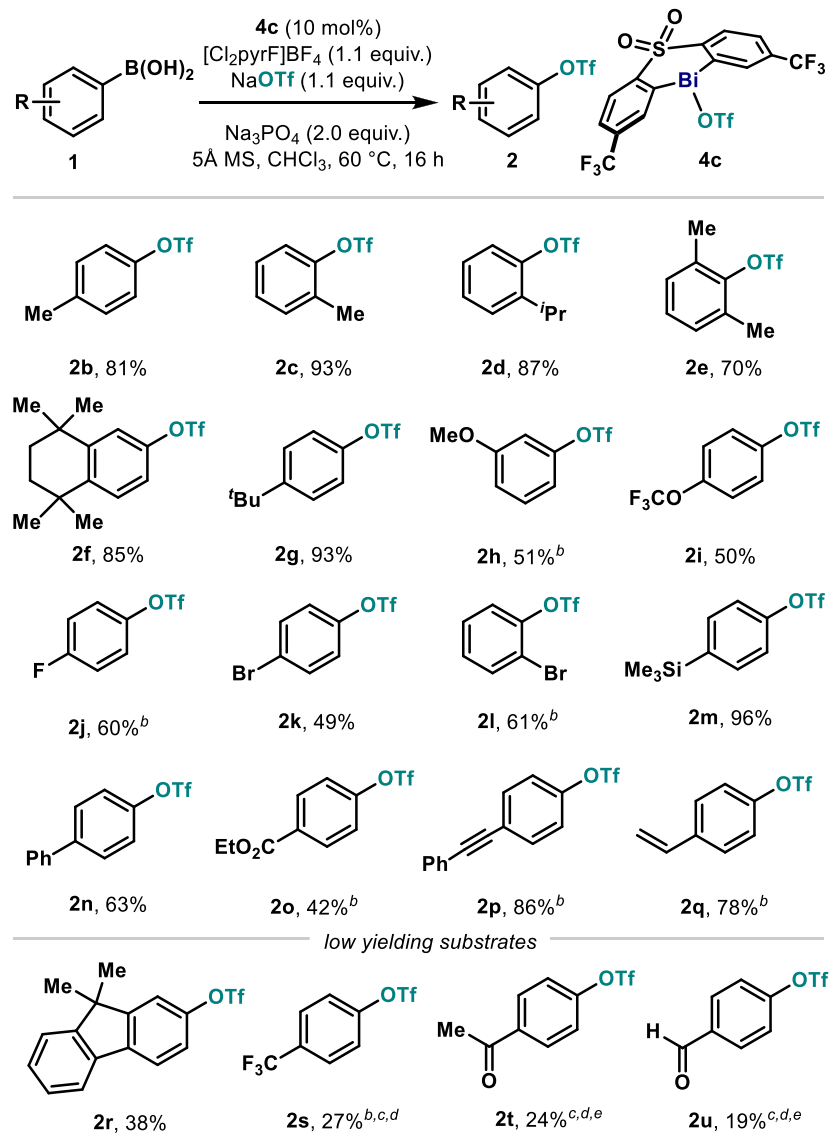

${ }^{a}$ Reaction conditions: 1 (0.3 mmol), NaOTf $(0.33 \mathrm{mmol}), 4 \mathrm{c}(0.03$ $\mathrm{mmol}),\left[\mathrm{Cl}_{2} \mathrm{pyrF}\right] \mathrm{BF}_{4}(0.33 \mathrm{mmol}), \mathrm{Na}_{3} \mathrm{PO}_{4}(0.6 \mathrm{mmol})$, and $5 \AA$ MS $(120 \mathrm{mg})$ in $\mathrm{CHCl}_{3}$ at $60^{\circ} \mathrm{C}$ for $16 \mathrm{~h}$. Yields of isolated pure material. ${ }^{b}$ Reaction performed at $90{ }^{\circ} \mathrm{C}$ with 2.0 equiv of $\mathrm{NaF}$ as base. ${ }^{c}$ Yields determined by ${ }^{19} \mathrm{~F}$ NMR using 1-fluoro-4-nitrobenzene as internal standard. ${ }^{d}$ Reactions performed at $0.025 \mathrm{mmol}$ of the corresponding arylboronic acids. ${ }^{e}$ Reaction performed at $90{ }^{\circ} \mathrm{C}$ with 4.0 equiv of $\mathrm{Na}_{3} \mathrm{PO}_{4}$ as base.

methodology boded well with Me groups in both para- (2b) and ortho-positions (2c). Remarkably, when the steric encumbrance at the ortho-position was further increased, excellent yields of the corresponding triflate were obtained (2d and $2 \mathbf{e})$. Furthermore, the presence of alkyl moieties in other positions of the aryl ring did not affect the reactivity ( $2 \mathbf{f}$ and $\mathbf{2 g}$ ). The protocol accommodates various functional groups, including ethers ( $2 \mathbf{h}$ and $2 \mathbf{i})$ and halogens $(2 \mathbf{j}, 2 \mathbf{k}$, and $2 \mathbf{l})$, albeit in moderate yields. Arylboronic acids substituted with a trimethylsilyl group (TMS), $\mathrm{Ph}$, or an ester at the paraposition afforded good to excellent yields of the corresponding 
aryl triflates $(\mathbf{2} \mathbf{m}-\mathbf{2 o})$. Arylboronic acids bearing unsaturated moieties boded well in this methodology, as exemplified by the presence of alkynyl (2p) and vinyl (2q) groups. In spite of the large variety of arylboronic acids amenable for this transformation, moderate yields were obtained in the presence of certain functionalities. Due to the high reactivity toward oxidation with $\left[\mathrm{Cl}_{2} \mathrm{pyrF}\right] \mathrm{BF}_{4}$, fluorene derivative $2 \mathbf{r}$ was obtained in $38 \%$ yield. ${ }^{15}$ Substrates bearing strong electronwithdrawing groups such as $\mathrm{CF}_{3}$ (2s) and reactive carbonyl functionalities at the para-position ( $2 \mathbf{t}$ and $\mathbf{2 u}$ ) also struggled to undergo $\mathrm{C}-\mathrm{O}$ bond formation, demonstrating some limitations to the scope of this reaction.

Having established a protocol for the successful coupling of $\mathrm{NaOTf}$, we turned our attention to the use of less nucleophilic nonaflate salts as coupling partners. A brief re-examination of the reaction parameters revealed bismine nonaflate $\mathbf{4 d}$ as the catalyst of choice to couple arylboronic acids with commercially available KONf. ${ }^{15}$ With the optimized conditions shown in Table 3, Ph-ONf (5a) was isolated in a satisfactory

Table 3. Scope of the Bi-Catalyzed Oxidative Coupling of Arylboronic Acids and Potassium Nonaflate ${ }^{a}$

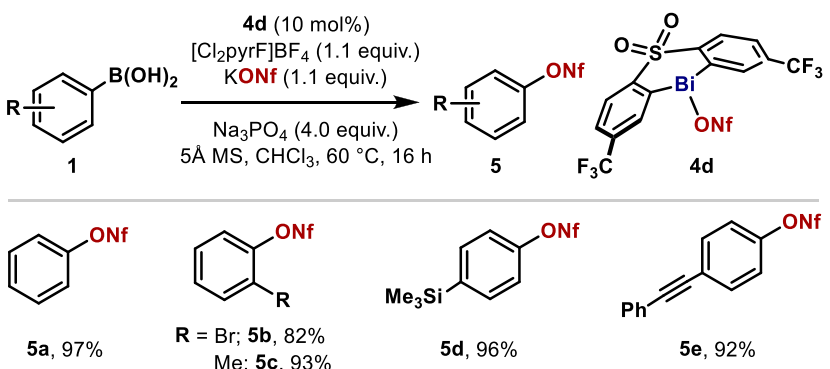

${ }^{a}$ Reaction conditions: 1 ( $\left.0.3 \mathrm{mmol}\right), \mathrm{KONf}(0.33 \mathrm{mmol}), \mathbf{4 d}(0.03$ $\mathrm{mmol}),\left[\mathrm{Cl}_{2} \mathrm{pyrF}\right] \mathrm{BF}_{4}(0.33 \mathrm{mmol}), \mathrm{Na}_{3} \mathrm{PO}_{4}(1.2 \mathrm{mmol})$ and $5 \AA \mathrm{MS}$ $(120 \mathrm{mg})$ in $\mathrm{CHCl}_{3}$ at $60{ }^{\circ} \mathrm{C}$ for $16 \mathrm{~h}$. Yields of isolated pure material.

97\% yield. The various arylboronic acids scrutinized in the nonaflate synthesis revealed comparable reactivity to NaOTf. Aryl nonaflates containing ortho-substituents such as $\mathrm{Br}(\mathbf{5 b})$ and $\mathrm{Me}(\mathbf{5 c})$ were obtained in excellent yields. Furthermore, a TMS moiety can also be accommodated to the protocol (5d) as well as unsaturated alkynyl functionalities (5e).

The unprecedented catalytic $\mathrm{C}-\mathrm{OTf}$ and $\mathrm{C}-\mathrm{ONf}$ bond forming reaction using $\mathbf{4 c}$ and $\mathbf{4 d}$ led us to explore the operative mechanism governing this transformation. First, we interrogated the transmetalation step between $\mathbf{1 a}$ and $4 \mathrm{c}$ (Figure 2A). When the reaction was performed in the presence of $\mathrm{Na}_{3} \mathrm{PO}_{4}$ and $5 \AA$ MS, transmetalation occurred efficiently and 6 was obtained in $86 \%$ yield (entry 1). In the absence of base, 6 was also obtained in slightly lower yields (62\%, entry $2)$. In sharp contrast, when the reaction was performed without MS (entry 3), formation of 6 was dramatically reduced (21\%). In the absence of both MS and $\mathrm{Na}_{3} \mathrm{PO}_{4}, 6$ was not detected. These results demonstrate the importance of molecular sieves in this transformation, not only as a dehydrating agent ${ }^{17}$ but also as a potential heterogeneous Brønsted base, ${ }^{18}$ promoting transmetalation to the $\mathrm{Bi}$ (III) center. At this point, the oxidation-reductive elimination sequence from phenylbismine 6 was studied utilizing different oxidants and triflate sources (Figure 2B, top). After oxidizing 6 with $\mathrm{XeF}_{2}$ to the high-valent $\mathrm{Bi}(\mathrm{V})$ difluoride species, ${ }^{10 \mathrm{~b}, 15}$ TMSOTf was added, resulting in a rapid color change from pale to dark yellow. Analysis of the

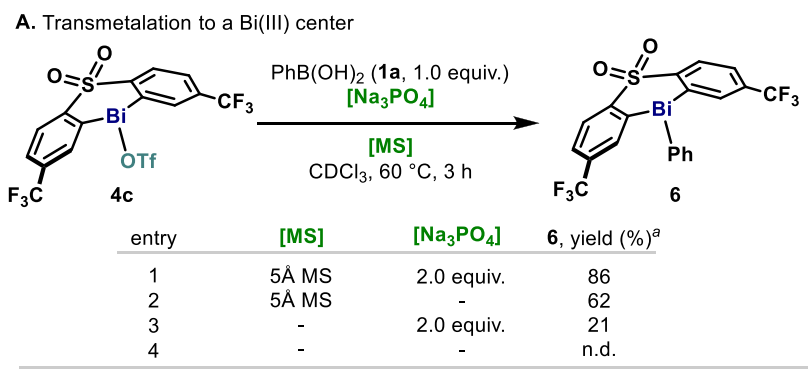

B. Oxidation-Reductive elimination sequence
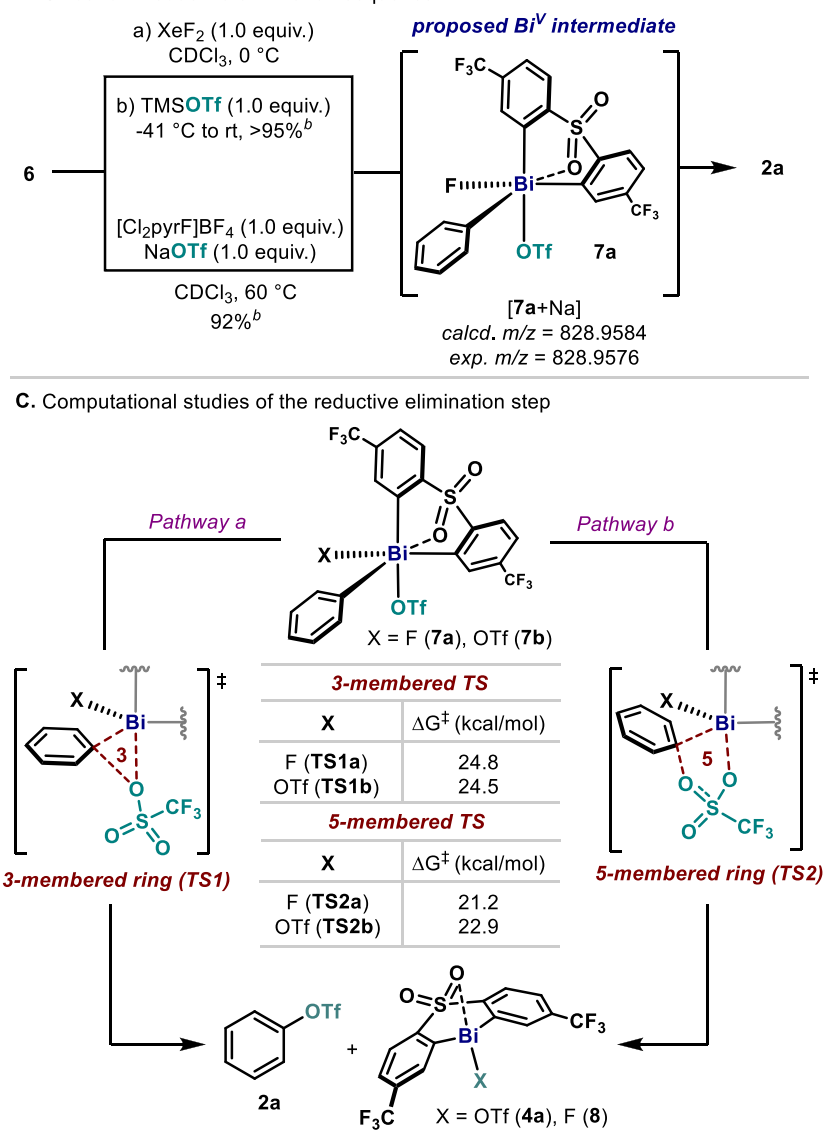

Figure 2. (A) Study of the transmetalation step: influence of the molecular sieves and the base. (B) Stoichiometric sequence of oxidative addition-reductive elimination. (C) Theoretical analysis of the $\mathrm{C}-\mathrm{O}$ bond forming step. ${ }^{a}$ Yields determined by ${ }^{1} \mathrm{H}$ NMR using 1,3,5-trimethoxybenzene as internal standard. ${ }^{b}$ Yields determined by ${ }^{19}$ F NMR using 1-fluoro-4-nitrobenzen as internal standard.

reaction crude revealed quantitative formation of $2 \mathbf{a}$. This result points to the formation of a highly electrophilic $\mathrm{Bi}(\mathrm{V})$ intermediate (7a) bearing an OTf moiety, as a consequence of fluoride abstraction by TMSOTf. Indeed, when TMSOTf was added at $-41{ }^{\circ} \mathrm{C}$, intermediate $7 \mathrm{a}$ could be detected by HRMS (Figure $2 \mathrm{~B}$ ). Furthermore, using $\left[\mathrm{Cl}_{2}\right.$ pyrF $] \mathrm{BF}_{4}$ as an oxidant together with $\mathrm{NaOTf}$ similar yields for $2 \mathrm{a}$ were obtained (92\%, Figure $2 \mathrm{~B}$, bottom). It is important to mention that only trace amounts of fluorobenzene were detected, which shows the preferential formation of $\mathrm{C}-\mathrm{OTf}$ over $\mathrm{C}-\mathrm{F}$ bonds (vide infra). ${ }^{19}$ Related intermediates have been previously postulated by Mukaiyama, in the $\mathrm{C}\left(\mathrm{sp}^{2}\right)-\mathrm{OTs}$ coupling from $\mathrm{Bi}(\mathrm{V})$ intermediates. ${ }^{14}$ Based on these experimental results, preliminary theoretical studies were performed to investigate a putative reductive elimination from 7 , bearing both a $\mathrm{F}(7 \mathbf{a})$ or an OTf $(7 \mathbf{b})$ as counterions. ${ }^{15}$ As shown in Figure $2 \mathrm{C}$, two 
possible scenarios were postulated. On one hand, reductive elimination can occur through a three-membered transition state (Figure 2C, pathway a), reminiscent of concerted reductive eliminations performed by d-block elements. Alternatively, reductive elimination could also occur via a five-membered transition state (Figure 2C, pathway $b$ ), where two oxygens of the OTf are involved. This latter hypothesis has been previously invoked to explain the selectivity of $\mathrm{Bi}$ mediated couplings such as $\alpha$-arylation of phenols ${ }^{20}$ and $N$ arylation of pyridones, $^{21}$ among other transformations. ${ }^{22}$ In accordance with these previous reports, our theoretical analysis predicts that the five-membered TS2 is slightly favored over TS1, pointing toward TS2 as the preferable pathway for the $\mathrm{C}-\mathrm{O}$ bond forming event. $\mathrm{NBO}$ analysis on the $\mathrm{Bi}$ center also provided additional information about this process. ${ }^{23}$ In the case of $7 \mathrm{a}$, the NBO charge on the Bi decreases from 2.17 to 1.84 in TS1 and 1.88 in TS2 and is further reduced to 1.50 in 8. The same trend is observed from $7 \mathbf{b} .{ }^{15}$ This progressive change in charge at the metal center has been previously observed in high-valent $\mathrm{Cu}$ cross-couplings, ${ }^{24}$ suggesting a concerted reductive elimination through the metal.

Taken these results together, the reaction is proposed to follow the catalytic cycle depicted in Figure 3. Initially, bismine

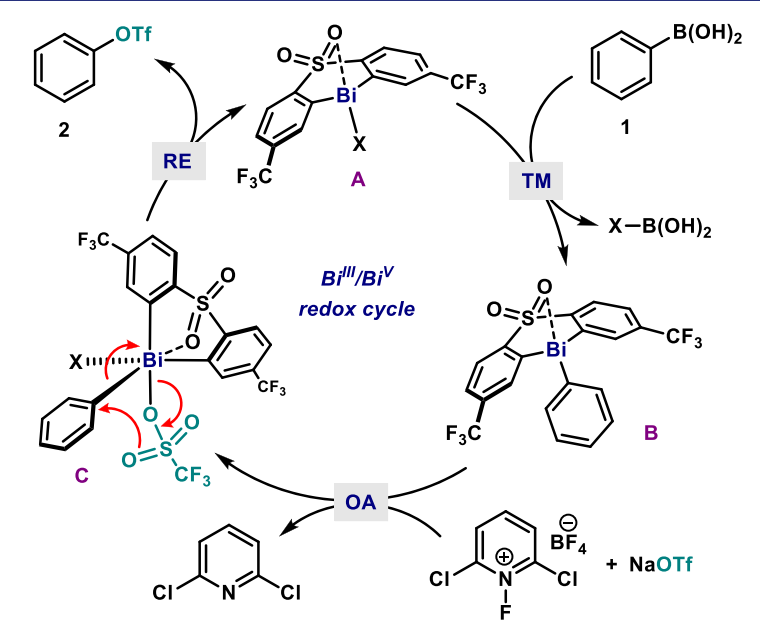

Figure 3. Postulated mechanism for the Bi-catalyzed oxidative coupling of arylboronic acids and triflate salts.

A undergoes transmetalation (TM) with the corresponding arylboronic acid, thus forming aryl bismine B. Subsequently, B undergoes formal oxidative addition $(\mathrm{OA})$ with $\left[\mathrm{Cl}_{2} \mathrm{pyrF}^{\mathrm{B}} \mathrm{BF}_{4}\right.$, furnishing the proposed high-valent $\mathrm{Bi}(\mathrm{V})$ intermediate $\mathrm{C}$. Reductive elimination (RE) from $\mathbf{C}$ delivers the desired aryl triflate with concomitant regeneration of $\mathbf{A}$. Due to the structural similarities between OTf and ONf, we believe that a similar mechanism is operating for the coupling of the latter.

In summary, an unprecedented oxidative coupling of arylboronic acids with triflate and nonaflate salts has been developed exploiting the reactivity of the $\mathrm{Bi}(\mathrm{III}) / \mathrm{Bi}(\mathrm{V})$ redox couple. A highly electron-withdrawing diarylsulfone ligand unlocked a catalytic process which proceeds under mild conditions and accommodates various functional groups. The results presented in this study unveil bismuth redox catalysis as a promising tool to perform transformations beyond the scope of transition metals, while mimicking their fundamental organometallic steps.

\section{ASSOCIATED CONTENT}

\section{(s) Supporting Information}

The Supporting Information is available free of charge at https://pubs.acs.org/doi/10.1021/jacs.0c05343.

Experimental procedures, analytical data $\left({ }^{1} \mathrm{H},{ }^{19} \mathrm{~F},{ }^{11} \mathrm{~B}\right.$, and ${ }^{13} \mathrm{C}$ NMR, HRMS) for all new compounds, computational results, including Tables (S1-S9) and Figures (S1-S20) (PDF)

\section{AUTHOR INFORMATION}

\section{Corresponding Author}

Josep Cornella - Max-Planck-Institut für Kohlenforschung, Mülheim an der Ruhr 45470, Germany; 이잉.org/00000003-4152-7098; Email: cornella@kofo.mpg.de

\section{Authors \\ Oriol Planas - Max-Planck-Institut für Kohlenforschung, Mülheim an der Ruhr 45470, Germany; 이이이.org/0000- 0003-2038-2678 \\ Vytautas Peciukenas - Max-Planck-Institut für Kohlenforschung, Mülheim an der Ruhr 45470, Germany; (1) orcid.org/0000-0001-7372-9650}

Complete contact information is available at: https://pubs.acs.org/10.1021/jacs.0c05343

\section{Notes}

The authors declare no competing financial interest.

\section{ACKNOWLEDGMENTS}

Financial support for this work was provided by Max-PlanckGesellschaft, Max-Planck-Institut für Kohlenforschung, Fonds der Chemischen Industrie (FCI-VCI). This project has received funding from European Union's Horizon 2020 research and innovation programme under Agreements Nos. 850496 (ERC Starting Grant, J.C.) and 833361 (Marie Skłodowska Curie Fellowship, O.P.). We thank Prof. Dr. A. Fürstner for insightful discussions and generous support. We also thank Dr. Kalishankar Bhattacharyya and Dr. Dimitrios Pantazis for insightful suggestions and support in the computational studies, as well as the analytical department at the MPI-Kohlenforschung for support in the characterization of compounds.

\section{REFERENCES}

(1) (a) Hansen, R. L. Perfluoroalkanesulfonate Esters as Alkylating Agents. J. Org. Chem. 1965, 30, 4322-4324. (b) Stang, P. J.; Hanack, M.; Subramanian, L. R. Perfluoroalkanesulfonic Esters: Methods of Preparation and Applications in Organic Chemistry. Synthesis 1982, 1982, 85-126. (c) Ritter, K. Synthetic Transformations of Vinyl and Aryl Triflates. Synthesis 1993, 1993, 735-762. (d) Högermeier, J.; Reissig, H.-U. Nine Times Fluoride can be Good for your Syntheses. Not just Cheaper: Nonafluorobutanesulfonates as Intermediates for Transition Metal-Catalyzed Reactions. Adv. Synth. Catal. 2009, 351 (17), 2747-2763.

(2) (a) Zeni, G.; Larock, R. C. Synthesis of Heterocycles via Palladium-Catalyzed Oxidative Addition. Chem. Rev. 2006, 106, 4644-4680. (b) Rosen, B. M.; Quasdorf, K. W.; Wilson, D. A.; Zhang, N.; Resmerita, A.-M.; Garg, N. K.; Percec, V. Nickel-Catalyzed Cross-Couplings Involving Carbon-Oxygen Bonds. Chem. Rev. 2011, 111, 1346-1416. (c) Bisz, E.; Szostak, M. Iron-Catalyzed C-O Bond Activation: Opportunity for Sustainable Catalysis. ChemSusChem 2017, 10, 3964-3981.

(3) For representative transition-metal catalyzed C-OTf and CONf functionalization reactions, see: (a) Echavarren, A. M.; Stille, J. 
K. Palladium-catalyzed coupling of aryl triflates with organostannanes. J. Am. Chem. Soc. 1987, 109, 5478-5486. (b) Ohe, T.; Miyaura, N.; Suzuki, A. Palladium-catalyzed cross-coupling reaction of organoboron compounds with organic triflates. J. Org. Chem. 1993, 58, 2201-2208. (c) Wolfe, J. P.; Buchwald, S. L. Palladium-Catalyzed Amination of Aryl Triflates. J. Org. Chem. 1997, 62, 1264-1267. (d) Rottländer, M.; Knochel, P. Palladium-Catalyzed Cross-Coupling Reactions with Aryl Nonaflates: A Practical Alternative to Aryl Triflates. J. Org. Chem. 1998, 63, 203-208. (e) Anderson, K. W.; Mendez-Perez, M.; Priego, J.; Buchwald, S. L. Palladium-Catalyzed Amination of Aryl Nonaflates. J. Org. Chem. 2003, 68, 9563-9573. (f) Lee, D.-Y.; Hartwig, J. F. Zinc Trimethylsilylamide as a Mild Ammonia Equivalent and Base for the Amination of Aryl Halides and Triflates. Org. Lett. 2005, 7, 1169-1172. (g) Gooßen, L. J.; Rodríguez, N.; Linder, C. Decarboxylative Biaryl Synthesis from Aromatic Carboxylates and Aryl Triflates. J. Am. Chem. Soc. 2008, 130, 15248-15249. (h) Uemura, M.; Yorimitsu, H.; Oshima, K. $\mathrm{Cp} * \mathrm{Li}$ as a base: application to palladium-catalyzed cross-coupling reaction of aryl-X or alkenyl-X $(\mathrm{X}=\mathrm{I}, \mathrm{Br}, \mathrm{OTf}, \mathrm{ONf})$ with terminal acetylenes. Tetrahedron 2008, 64, 1829-1833. (i) Watson, D. A.; Su, M.; Teverovskiy, G.; Zhang, Y.; García-Fortanet, J.; Kinzel, T.; Buchwald, S. L. Formation of $\operatorname{ArF}$ from LPdAr(F): Catalytic Conversion of Aryl Triflates to Aryl Fluorides. Science 2009, 325, 1661-1664. (j) Gooßen, L. J.; Linder, C.; Rodríguez, N.; Lange, P. P. Biaryl and Aryl Ketone Synthesis via Pd-Catalyzed Decarboxylative Coupling of Carboxylate Salts with Aryl Triflates. Chem. - Eur. J. 2009, 15, 9336-9349. (k) Shekhar, S.; Dunn, T. B.; Kotecki, B. J.; Montavon, D. K.; Cullen, S. C. A General Method for PalladiumCatalyzed Reactions of Primary Sulfonamides with Aryl Nonaflates. $J$. Org. Chem. 2011, 76, 4552-4563. (1) Si, T.; Li, B.; Xiong, W.; Xu, B.; Tang, W. Efficient cross-coupling of aryl/alkenyl triflates with acyclic secondary alkylboronic acids. Org. Biomol. Chem. 2017, 15, 99039909.

(4) Krossing, I.; Raabe, I. Noncoordinating Anions-Fact or Fiction? A Survey of Likely Candidates. Angew. Chem., Int. Ed. 2004, 43, 2066-2090.

(5) (a) Hartwig, J. F. Organotransition metal chemistry: From bonding to catalysis; University Science Books: Mill Valley, CA, 2010. (b) Maleckis, A.; Sanford, M. S. Facial Tridentate Ligands for Stabilizing Palladium(IV) Complexes. Organometallics 2011, 30, 6617-6627. (c) Racowski, J. M.; Gary, J. B.; Sanford, M. S. Carbon $\left(\mathrm{sp}^{3}\right)$-Fluorine Bond-Forming Reductive Elimination from Palladium(IV) Complexes. Angew. Chem., Int. Ed. 2012, 51, 34143417.

(6) Dhakal, B.; Bohé, L.; Crich, D. Trifluoromethanesulfonate Anion as Nucleophile in Organic Chemistry. J. Org. Chem. 2017, 82, 92639269.

(7) (a) Lawrance, G. A. Coordinated trifluoromethanesulfonate and fluorosulfate. Chem. Rev. 1986, 86, 17-33. (b) Beck, W.; Suenkel, K. Metal complexes of weakly coordinating anions. Precursors of strong cationic organometallic Lewis acids. Chem. Rev. 1988, 88, 1405-1421. (c) Ball, N. D.; Kampf, J. W.; Sanford, M. S. Aryl- $\mathrm{CF}_{3}$ Bond-Forming Reductive Elimination from Palladium(IV). J. Am. Chem. Soc. 2010, 132, 2878-2879. (d) Lyons, T. W.; Sanford, M. S. PalladiumCatalyzed Ligand-Directed C-H Functionalization Reactions. Chem. Rev. 2010, 110, 1147-1169. (e) Canty, A. J. Higher Oxidation State Organopalladium and Platinum Chemistry; Springer-Verlag: Berlin, Heidelberg, Germany, 2011.

(8) (a) Bour, J. R.; Camasso, N. M.; Sanford, M. S. Oxidation of $\mathrm{Ni}(\mathrm{II})$ to $\mathrm{Ni}(\mathrm{IV})$ with Aryl Electrophiles Enables Ni-Mediated Aryl$\mathrm{CF}_{3}$ Coupling. J. Am. Chem. Soc. 2015, 137, 8034-8037. (b) Camasso, N. M.; Sanford, M. S. Design, synthesis, and carbon-heteroatom coupling reactions of organometallic nickel(IV) complexes. Science 2015, 347, 1218-1220. (c) Canty, A. J.; Ariafard, A.; Camasso, N. M.; Higgs, A. T.; Yates, B. F.; Sanford, M. S. Computational study of $\mathrm{C}\left(\mathrm{sp}^{3}\right)-\mathrm{O}$ bond formation at a $\mathrm{Pd}^{\mathrm{IV}}$ centre. Dalton Trans 2017, 46, 3742-3748. (d) Nebra, N. High-Valent $\mathrm{Ni}^{\mathrm{III}}$ and $\mathrm{Ni}^{\mathrm{IV}}$ Species Relevant to $\mathrm{C}-\mathrm{C}$ and $\mathrm{C}-$ Heteroatom Cross-Coupling Reactions: State of the Art. Molecules 2020, 25, 1141.
(9) Suero, M. G.; Bayle, E. D.; Collins, B. S. L.; Gaunt, M. J. CopperCatalyzed Electrophilic Carbofunctionalization of Alkynes to Highly Functionalized Tetrasubstituted Alkenes. J. Am. Chem. Soc. 2013, 135, 5332-5335.

(10) (a) Wang, F.; Planas, O.; Cornella, J. Bi(I)-Catalyzed TransferHydrogenation with Ammonia-Borane. J. Am. Chem. Soc. 2019, 141, 4235-4240. (b) Planas, O.; Wang, F.; Leutzsch, M.; Cornella, J. Fluorination of arylboronic esters enabled by bismuth redox catalysis. Science 2020, 367, 313-317.

(11) (a) Power, P. P. Main-group elements as transition metals. Nature 2010, 463, 171-177. (b) Weetman, C.; Inoue, S. The Road Travelled: After Main-Group Elements as Transition Metals. ChemCatChem 2018, 10, 4213-4228. (c) Melen, R. L. Frontiers in molecular p-block chemistry: From structure to reactivity. Science 2019, 363, 479-484. (d) Janssen-Müller, D.; Oestreich, M. Transition-Metal-Like Catalysis with a Main-Group Element: Bismuth-Catalyzed C-F Coupling of Aryl Boronic Esters. Angew. Chem., Int. Ed. 2020, 59, 8328-8330.

(12) (a) Stewart, C. A.; Calabrese, J. C.; Arduengo, A. J. Synthesis and structure of the first $20-\mathrm{Bi}-9$ system: a discrete nine-coordinate 20-electron bismuth. J. Am. Chem. Soc. 1985, 107, 3397-3398. (b) Boyer, B.; Keramane, E. M.; Montero, J.-L.; Roque, J.-P. BiCl 3 : An Efficient Agent for Selective Chlorination of Alcohols or for Halogen Exchange Reaction. Synth. Commun. 1998, 28, 1737-1741. (c) Matano, Y.; Nomura, H. Dimeric Triarylbismuthane Oxide: A Novel Efficient Oxidant for the Conversion of Alcohols to Carbonyl Compounds. J. Am. Chem. Soc. 2001, 123, 6443-6444. (d) Yin, S.-F.; Maruyama, J.; Yamashita, T.; Shimada, S. Efficient Fixation of Carbon Dioxide by Hypervalent Organobismuth Oxide, Hydroxide, and Alkoxide. Angew. Chem., Int. Ed. 2008, 47, 6590-6593. (e) Raţ, C. I.; Silvestru, C.; Breunig, H. J. Hypervalent organoantimony and -bismuth compounds with pendant arm ligands. Coord. Chem. Rev. 2013, 257, 818-879.

(13) For selected recent examples of Bi-OTf species, see: (a) Tschersich, C.; Hoof, S.; Frank, N.; Herwig, C.; Limberg, C. The Effect of Substituents at Lewis Acidic Bismuth(III) Centers on Its Propensity to Bind a Noble Metal Donor. Inorg. Chem. 2016, 55, 1837-1842. (b) Kannan, R.; Kumar, S.; Andrews, A. P.; Jemmis, E. D.; Venugopal, A. Consequence of Ligand Bite Angle on Bismuth Lewis Acidity. Inorg. Chem. 2017, 56, 9391-9395. (c) Ritschel, B.; Poater, J.; Dengel, H.; Bickelhaupt, F. M.; Lichtenberg, C. Double CH Activation of a Masked Cationic Bismuth Amide. Angew. Chem., Int. Ed. 2018, 57, 3825-3829. (d) Ramler, J.; Poater, J.; Hirsch, F.; Ritschel, B.; Fischer, I.; Bickelhaupt, F. M.; Lichtenberg, C. Carbon monoxide insertion at a heavy p-block element: unprecedented formation of a cationic bismuth carbamoyl. Chem, Sci. 2019, 10, 4169-4176. (e) Ramler, J.; Hofmann, K.; Lichtenberg, C. Neutral and Cationic Bismuth Compounds: Structure, Heteroaromaticity, and Lewis Acidity of Bismepines. Inorg. Chem. 2020, 59, 3367-3376.

(14) (a) Imachi, S.; Mukaiyama, T. Oxidative Coupling of Carbonyl Compounds by Using Pentavalent Biphenyl-2,2'-ylenebismuth Reagents. Chem. Lett. 2007, 36, 718-719. (b) Sakurai, N.; Mukaiyama, T. A New Preparative Method of Aryl Sulfonate Esters by Using Cyclic Organobismuth Reagents. Heterocycles 2007, 74, $771-790$.

(15) See Supporting Information for further details.

(16) Jurrat, M.; Maggi, L.; Lewis, W.; Ball, L. T. Modular bismacycles for the selective $\mathrm{C}-\mathrm{H}$ arylation of phenols and naphthols. Nat. Chem. 2020, 12, 260-269.

(17) West, M. J.; Fyfe, J. W. B.; Vantourout, J. C.; Watson, A. J. B. Mechanistic Development and Recent Applications of the Chan-Lam Amination. Chem. Rev. 2019, 119, 12491-12523.

(18) Steinhoff, B. A.; King, A. E.; Stahl, S. S. Unexpected Roles of Molecular Sieves in Palladium-Catalyzed Aerobic Alcohol Oxidation. J. Org. Chem. 2006, 71, 1861-1868.

(19) Furuya, T.; Kamlet, A.; Ritter, T. Catalysis for fluorination and trifluoromethylation. Nature 2011, 473, 470-477.

(20) Barton, D. H. R.; Bhatnagar, N. Y.; Finet, J.-P.; Motherwell, W. B. Pentavalent organobismuth reagents. Part VI. Comparative 
migratory aptitudes of aryl groups in the arylation of phenols and enols by pentavalent bismuth reagents. Tetrahedron 1986, 42, 31113122.

(21) Ikegai, K.; Mukaiyama, T. Synthesis of N-Aryl Pyridin-2-ones via Ligand Coupling Reactions Using Pentavalent Organobismuth Reagents. Chem. Lett. 2005, 34, 1496-1497.

(22) (a) Finet, J.-P. Ligand Coupling Reactions with Heteroatomic Compounds; Elsevier: Oxford, 1998. (b) Finet, J.-P. Arylation reactions with organobismuth reagents. Chem. Rev. 1989, 89, 14871501.

(23) (a) Reed, A. E.; Curtiss, L. A.; Weinhold, F. Intermolecular interactions from a natural bond orbital, donor-acceptor viewpoint. Chem. Rev. 1988, 88, 899-926. (b) Weinhold, F.; Landis, C. R. Valency and Bonding: A Natural Bond Orbital Donor-Acceptor Perspective; Cambridge University Press: Cambridge, United Kingdom, 2005.

(24) Paeth, M.; Tyndall, S. B.; Chen, L.-Y.; Hong, J.-C.; Carson, W. P.; Liu, X.; Sun, X.; Liu, J.; Yang, K.; Hale, E. M.; Tierney, D. L.; Liu, B.; Cao, Z.; Cheng, M.-J.; Goddard, W. A.; Liu, W. Csp ${ }^{3}-\mathrm{Csp}^{3}$ BondForming Reductive Elimination from Well-Defined Copper(III) Complexes. J. Am. Chem. Soc. 2019, 141, 3153-3159. 